\title{
Tumor necrosis factor alpha as a marker of systemic and local inflammation in "healthy" smokers
}

\author{
Juan M Diez-Pina' \\ María J Fernandez-Aceñero ${ }^{3}$ \\ María J Llorente-Alonso ${ }^{2}$ \\ Salvador Diaz-Lobato 4 \\ Sagrario Mayoralas' \\ Asuncion Florez' \\ 'Department of Pneumology; \\ ${ }^{2}$ Department of Biochemistry, \\ Hospital de Móstoles, Móstoles, \\ Madrid, Spain; ${ }^{3}$ Department \\ of Pathology, Fundacion \\ Jiménez-Díaz, Madrid, Spain; \\ ${ }^{4}$ Department of Pneumology, Hospital \\ Ramón y Cajal, Madrid, Spain
}

Background: Tobacco smoking induces a local and systemic inflammatory reaction and also a decline in pulmonary function. There are some novel noninvasive methods to measure the degree of inflammatory bronchial reaction, including the exhaled breath condensate (EBC) in which several inflammatory markers can be measured, including tumor necrosis factor alpha (TNF- $\alpha$ ). There is a clear clinical need to develop methods that allow early detection of smokers at risk of losing pulmonary function.

Objectives: The aims of the present study are: 1) to show that smokers show higher levels of TNF- $\alpha$ both in serum and EBC; 2 ) to analyze the possible influence of gender, age, and weight on this parameter; and 3 ) to determine a possible association between smoking and pulmonary function parameters and TNF- $\alpha$ levels.

Material and methods: We have prospectively analyzed two cohorts of smokers and nonsmokers subjects without any chronic or acute disease (within eight weeks of study initiation). We have performed pulmonary function tests with bronchodilators and also collected EBC and blood samples before smoking cessation. Statistical analysis was performed with SPSS 11.0 for Windows Statistical Package.

Results: The study has enrolled 17 patients ( 8 smokers), 50\% of whom were females. Mean age was 38.59 years old (standard deviation, 7.4). The mean number of cigarettes smoked in the smoker group was 26.14 (11.29) cigarettes/day and the mean age when tobacco first began was 15.14 (2.04) years. We have not been able to show any significant differences in TNF- $\alpha$ levels according to age or weight. For the whole series we have not found any significant influence of gender in TNF- $\alpha$ levels, but after dividing the series in smokers and nonsmokers, we have shown higher levels of TNF- $\alpha$ in serum $(5.59$ [0.26] pg/mL vs 5.56 [0.37] pg/mL; nonsignificant [NS]) and EBC (4.94 [0.41] pg/mL vs 4.22 [0.36] pg/mL; $\mathrm{p}=0.031)$ in male smokers. On the other hand, nonsmoking females showed slightly higher TNF- $\alpha$ levels in serum $(5.70[0.50] \mathrm{pg} / \mathrm{mL}$ vs $5.42[0.29] \mathrm{pg} / \mathrm{mL}$; NS) and EBC (4.54 [0.92] vs 4.11 [0.41 pg/mL]; NS). Smokers had higher TNF- $\alpha$ levels in EBC $(4.46[0.58] \mathrm{pg} / \mathrm{mL}$ vs 4.34 [0.62] pg/mL; NS), while serum TNF- $\alpha$ levels were slightly higher in nonsmokers $(5.52[0.56] \mathrm{pg} / \mathrm{mL}$ vs $5.50[0.27] \mathrm{pg} / \mathrm{mL} ; \mathrm{NS})$. We have not demonstrated any association between tobacco consumption and TNF- $\alpha$ levels. We have not shown any significant relation between pulmonary function and the studied parameters, with only a modest association between forced expiratory volume at one second and forced vital capacity and TNF- $\alpha$ levels in EBC.

Conclusion: Smokers show higher TNF- $\alpha$ levels in EBC. Among smokers, males show higher levels of TNF in serum and EBC. We have not confirmed any significant influence of age or weight on TNF- $\alpha$ levels. These levels do not seem to be influenced either by the amount of tobacco or the time since habit began. We have shown a modest relation between pulmonary function and TNF- $\alpha$ levels in EBC.

Keywords: inflammatory markers, tumor necrosis factor, exhaled breath condensate, cigarette smoking

\section{Introduction}

Oxidative stress is a basic component of the airways inflammatory reaction in patients with chronic obstructive pulmonary disease (COPD). Its pathogenesis seems
Correspondence: Juan M Diez-Pina

Neumología, Hospital de Móstoles,

Móstoles, Madrid, Spain

Email jmdpas@hotmail.com 
to be related to the loss of balance between oxidants and antioxidants. ${ }^{1}$ Oxidative stress seems to be augmented in healthy smokers and tobacco smoking is the main risk factor for the development of COPD. ${ }^{2}$

Traditional methods to collect samples from the lower airways include induced sputum and bronchoscopy with bronchoalveolar lavage (BAL). There are not many noninvasive methods to measure inflammatory reaction in the airways. In recent years there has been a growing interest in the use of exhaled breath condensate (EBC), which is a noninvasive method that allows repeated sample collection. ${ }^{3,4}$ The condensate is supposed to reflect the composition of the bronchoalveolar extracellular fluid, in which there are some nonvolatile substances and up to 200 volatile ones. ${ }^{5,6}$ Among the nonvolatile molecules we can find in the condensate we can mention proteins, lipids, oxidants, and nucleotides. To measure these substances we first cool the exhaled breath to obtain a condensate. The molecules we measure are markers for different pulmonary disorders. Among the different markers of oxidative stress and/or inflammatory mediators that have been measured in the EBC of healthy subjects and also in patients with different kind of airway disorders, we can mention 8-isoprostane, leukotrienes, and prostaglandins. Nevertheless, this technique is still associated with some difficulties for sample collection and also for the analysis and interpretation of the exhaled breath condensate, which should be taken into account. ${ }^{3,7}$

Cytokines act as signalling molecules in the immune system and also in other body systems, as part of a complex network participating in the immune response. Several proinflammatory cytokines have been detected in the BAL fluid (IL-1 $\beta$, TNF- $\alpha$ ), and also neutrophile chemotactic cytokines (IL-8) and anti-inflammatory cytokines (IL-10). ${ }^{8}$ The same kind of cytokines have been also found in the EBC of healthy subjects, but they have been different from those reported in patients with pulmonary inflammatory disorders. ${ }^{9}$

Tumor necrosis factor alpha $(\mathrm{TNF}-\alpha)$ is a powerful proinflammatory cytokine, considered important for neutrophiles recruitment, that is elevated in COPD patients. ${ }^{10,11}$ Systemic hypoxemia is associated with the activation of the TNF- $\alpha$ system in COPD patients and this cytokine has been reported as an important etiopathogenic factor in the lung damage secondary to smoking. ${ }^{12}$

There is a clinical need to find novel markers of early inflammatory change that allow detection of the population at risk of developing pulmonary disorders, so that preventive measures can be initiated before irreversible damage has taken place. The aim of the present study is to show whether "healthy" smokers show higher levels of local and systemic inflammatory markers as compared with nonsmokers and also to analyze the possible influence of antropometric features, tobacco consumption, and pulmonary function values on these markers.

\section{Material and methods}

We have designed an observational analytical prospective cohort study with two cohorts: one of healthy smokers and another of healthy nonsmokers. The study group enrolled smokers that were consulted for the first time in our smoking cessation clinic and the comparison group corresponded to healthy hospital workers that had never smoked. We obtained written signed consent from all the subjects participating in the study. This study was approved by the Ethical Committee of our Hospital.

In both groups we obtained a thorough history, including prescription drug consumption and also a physical examination. The inclusion criteria for our study were absence of any previous disease or regular use of drugs in the eight weeks prior to the study initiation. In the smokers group we discarded mainly signs and symptoms suggestive of a chronic bronchitis and/or bronchial hyperreactivity. Patients that fulfilled inclusion criteria underwent a forced spirometry (Jaeger MS Body/diff Master Screen; Jaeger, Hoechberg, Germany) following the recommendations set forth by different authors, in order to confirm that pulmonary function was normal. We also performed pulmonary function tests after bronchodilatation with salbutamol to exclude reversibility, according to previously established criteria. ${ }^{13}$

We have collected a sample of exhaled breath and blood; in the smokers these samples were collected before giving up tobacco consumption. To collect the EBC we have employed a commercially-available condenser (Ecoscreen; Jaeger). All the collections were performed under the same conditions of temperature and humidity. Smokers refrained from smoking 8-10 hours before the collection. The patients were asked to take several breaths at tidal volume without nose clipping, inspirating and exhaling the air through the mouth, for 15-20 minutes or until total volume reached $200 \mathrm{ml}$.

The serum and exhaled breath samples were kept at $-70^{\circ} \mathrm{C}$ until analysis. TNF- $\alpha$ was determined in both fluids with ELISA immunoassay (DRG Diagnostics GMBH, Germany). We have employed different monoclonal antibodies against different epitopes in the TNF- $\alpha$ molecule. The anti-TNF- $\alpha$ conjugate was labelled with horseradish peroxidase (HRP), a TRIS maleate buffer with bovine albumin, EDTA and timol. Tetramethylbenzidine in dimethylformamide (TMB) 
was used as chromogen. TNF- $\alpha$ level is proportional to the intensity of the color generated in this reaction and is estimated by interpolating the value in the calibration curve to 5 points. We have performed a bichromatic reading of the microtiter plate at $450 \mathrm{~nm}$ comparing it against a reference filter of $620 \mathrm{~nm}$. The assay was automatized in DSX (Dynex Technology, Chantilly, VA, USA).

The results of the study were analyzed with SPSS 11.0 for Windows Statistical Analysis Package (SPSS Inc., Chicago, IL, USA). After verifying normality of the distribution with Kolmogorov-Smirnov test, descriptive statistics included mean (standard deviation) for parametric quantitative variables or median (range) for nonparametric ones. Qualitative variables were described with absolute numbers and percentages. Bivariate analysis include Student's t test or ANOVA for mean comparison or their corresponding nonparametric tests (Mann-Whitney's U or Kruskall-Wallis test). Association between qualitative variables was analysed with the squared-chi test. Correlation between quantitative variables was analyzed with Pearson's $r$ for parametric ones and Spearman's rho for nonparametric ones. The significance value was set in all the cases at a $\mathrm{p}<0.05$ value.

For the graphic representation of our data we have chosen the box-plot diagram, representing the median and the 25th and 75 th percentile values for the variables in the central box and outlier variables.

\section{Results}

We enrolled 17 patients in this study. Table 1 summarizes the demographic features of these patients and also the data

Table I Demographic features of the control and study group. The numbers correspond to mean (standard deviation)

\begin{tabular}{llll}
\hline & Smokers & Nonsmokers & p value \\
\hline N: I7 & 8 & 9 & \\
Age (years) & $43.57(5.68)$ & $35.10(6.56)$ & 0.015 \\
Gender & Male: 4 & Male: 5 & 0.52 \\
& Female: 4 & Female: 4 & \\
Weight $(\mathrm{kg})$ & $79.01(27.60)$ & $73.56(16.56)$ & 0.63 \\
BMl $\left(\mathrm{kg} / \mathrm{m}^{2}\right)$ & $27.78(6.67)$ & $24.72(3.27)$ & 0.30 \\
FVC $(\mathrm{ml})$ & $4232.86(992.77)$ & $4778.89(924.76)$ & 0.275 \\
FVC $(\%)$ & $99.77(13.50)$ & $97.42(9.96)$ & 0.694 \\
FEV $(\mathrm{ml})$ & $3424.29(777.28)$ & $4015.56(669.68)$ & 0.124 \\
FEV $_{1}(\%)$ & $104.60(16.97)$ & $104.21(10.59)$ & 0.95 \\
FEV $_{1} /$ FVC & $8 I .31(5.16)$ & $84.41(4.23)$ & 0.207 \\
\hline
\end{tabular}

Abbreviations: $\mathrm{BMI}$, body mass index; $\mathrm{FEV}_{1}$, forced respiratory volume in one second FVC, forced vital capacity. related to pulmonary function. Smokers had a mean cigarette consumption of 26.14 cigarettes per day (SD: 11.29); the mean age when smoking first began was 15.14 (SD: 2.03) and the mean cumulative consumption index was 37.43 (17.28) packages/year.

We did not find differences in TNF- $\alpha$ levels in EBC between smokers and nonsmokers $(4.46[0.58] \mathrm{pg} / \mathrm{mL}$ vs 4.34 [0.62] pg/mL). TNF- $\alpha$ levels in serum did not show either differences between the two groups $(5.52[0.56] \mathrm{pg} / \mathrm{mL}$ vs $5.50[0.27] \mathrm{pg} / \mathrm{mL}$ ) (Figure 1).

When we compared the TNF- $\alpha$ levels between genders (without considering whether they smoked) we did not find any significant differences in any of the parameters (Figure 2). We did not find any significant association either between TNF- $\alpha$ levels in both kind of samples and the patients' age or weight.
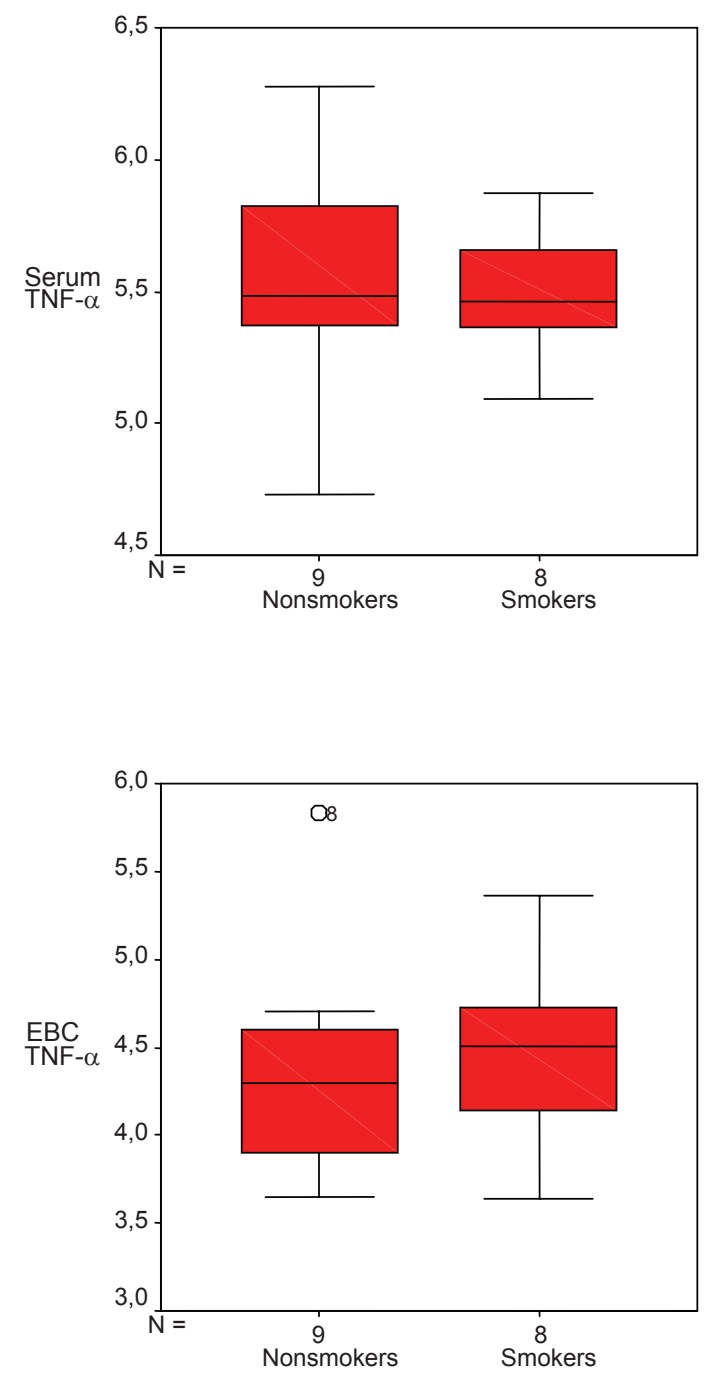

Figure I Tumor necrosis factor alpha (TNF- $\alpha$ ) levels in serum and exhaled breath condensate $(\mathrm{EBC})$ in smokers and nonsmokers. 

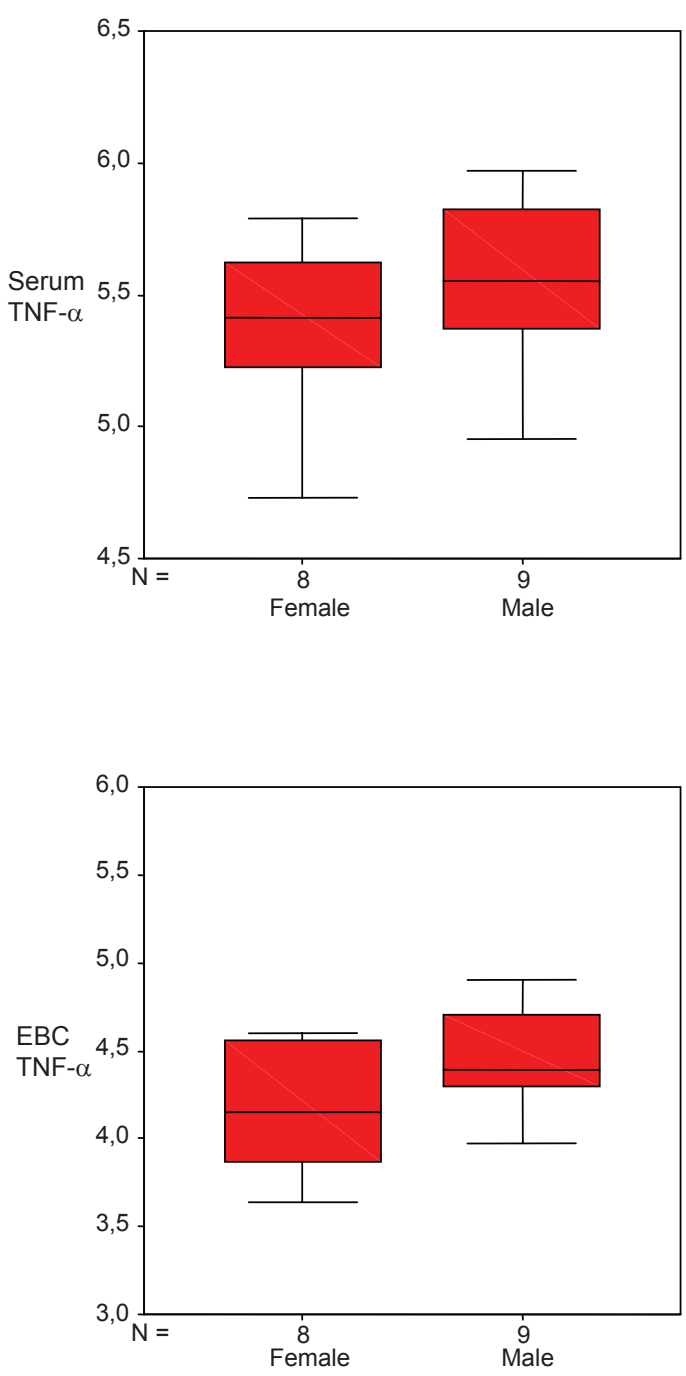

Figure 2 Tumor necrosis factor alpha (TNF- $\alpha$ ) in serum and exhaled breath condensate $(E B C)$ in both genders.

However, when we divided our series in two groups according to the smoking habits of the patients, we found that male smokers had higher TNF- $\alpha$ levels than male nonsmokers in EBC (4.94 [0.41] vs 4.22 [0.36] pg/mL; $\mathrm{p}=0.031$ ), but not in serum $(5.59$ [0.26] vs $5.56[0.37] \mathrm{pg} / \mathrm{mL}$; NS difference). On the other hand, no differences were found for nonsmoker females in TNF- $\alpha$ levels in serum (5.70 [0.50] vs 5.42 [0.29] pg/mL; NS) nor in EBC (4.54 [0.92] vs 4.11 [0.41] pg/mL; NS) (Figure 3).

When we analyzed the possible association with pulmonary function parameters, we found only an statistically significant association between porcentual values of the forced vital capacity (FVC) and forced respiratory volume in one second $\left(\mathrm{FEV}_{1}\right)$ and mean TNF- $\alpha$ levels in EBC for the whole series ( $r$ values $=-0.41$ and -0.45 , with $p$ values for the correlations 0.031 and 0.013 , respectively). When we considered for the analysis whether the patients smoked, we found that in the control group no TNF- $\alpha$ levels was significantly associated with tests measuring lung function. In the study group we found a trend toward significance for the possible association between TNF- $\alpha$ levels in EBC and $\mathrm{FEV}_{1}$ and $\mathrm{FVC}(\mathrm{r}=-0.074$ and 0.70 with $\mathrm{p}=0.058$ and 0.079 , respectively) (Table 2 ).

In the study group we have also analyzed the influence of tobacco consumption (number of cigarettes a day and age at consumption initiation) and TNF- $\alpha$ levels, but we did not find any significant association between these parameters ( $\mathrm{r}$ values 0.46 and 0.138 for $\mathrm{EBC}$ and $\mathrm{r}$ values 0.94 and 0.52 for serum TNF- $\alpha$ with $p>0.05$, respectively).

\section{Discussion}

Cigarette smoking increases the intensity of oxidative stress, eventually leading to COPD. It would be necessary to measure the magnitude of local and systemic inflammation before an irreversible reduction of pulmonary function has taken place, for this could allow early identification of the patients at risk and also earlier and more energetic preventive interventions oriented toward tobacco cessation. Several reports have compared the levels of different inflammatory molecules, including TNF- $\alpha$ levels, in the EBC of smokers and nonsmokers. ${ }^{5,14,15}$

The techniques used to measure the intensity of inflammatory reaction in the distal airways have all been invasive until recent years. The use of EBC has allowed a noninvasive analysis of the composition of the fluid layer of the airways. However, this technique is still associated with some difficulties that hamper widespread use as a diagnostic tool for everyday practice, including lack of reproducibility, variability, possible influence of external factors (alcohol, smoking, drugs) and the difficulty to measure some substances present in the EBC after freezing. Besides, there are still no established reference values for the different parameters in the normal population or in patients with different lung disorders and yet there have been no studies that analyze the possible relation between altered levels of the inflammatory parameters and different symptoms or pulmonary function tests or the possible influence of different drugs on these inflammatory markers. ${ }^{4,16,17}$

Several volatile and nonvolatile substances that can serve to estimate the intensity of the local inflammatory reaction have been detected in samples from the EBC. One of them is TNF- $\alpha$, a proinflammatory cytokine that seems to be implied in pulmonary damage associated with smoking.

In our study we have found that serum TNF- $\alpha$ levels are not significantly different between smokers and nonsmokers, 

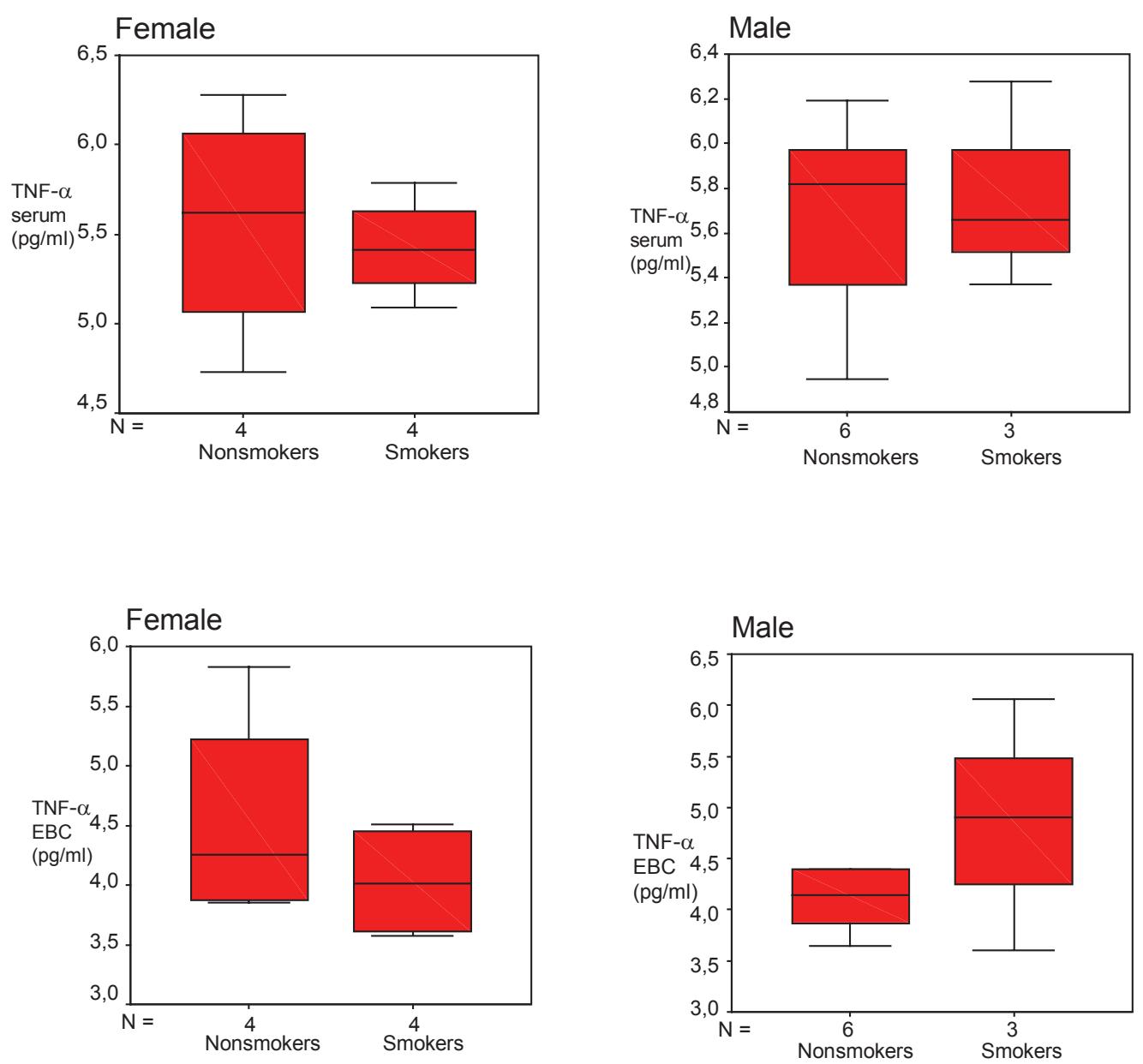

Figure 3 Tumor necrosis factor alpha (TNF- $\alpha$ ) in serum and exhaled breath condensate (EBC) in male/female considering the smoking status.

although they are slightly higher in nonsmokers. Vernooy and colleagues did not find either any significant differences in serum TNF- $\alpha$ levels between control patients and smokers with established COPD. ${ }^{18}$ Ryder and colleagues compared two groups of smokers and nonsmokers and exposed blood mononuclear cells from these groups to tobacco acutely in vitro, to subsequently measure the levels of TNF- $\alpha$ and other inflammatory markers. In this series the serum TNF- $\alpha$ levels were also higher in nonsmokers, as we have also shown, but again this difference did not reach significance. ${ }^{19}$ A possible explanation for this finding comes from a report by Mian and colleagues who showed an inhibitory effect of smoking on TNF- $\alpha$ production in vitro, that can be reversible. ${ }^{20}$

In our series the EBC TNF- $\alpha$ levels were higher in smokers; our results are in agreement with those reported by other authors in the literature. Sack and colleagues compared in one report the TNF- $\alpha$ levels in healthy smokers and nonsmokers and also in a group of patients with acute pulmonary distress due to severe pneumonia ventilated in the intensive care unit. These authors showed that TNF- $\alpha$ levels (and also other inflammatory cytokines, like IL-8 and IL-1) were higher in the ventilated patients compared with the other two groups. Besides, smokers had higher TNF- $\alpha$ levels in EBC than nonsmokers. ${ }^{9}$ Garey and colleagues have reported a study similar to ours in which they also confirm significantly higher TNF- $\alpha$ levels in the EBC of healthy smokers (7.4 vs $3.9 \mathrm{pg} / \mathrm{mL}$ ). ${ }^{14}$

The aforementioned studies have not analyzed the possible influence of tobacco consumption on these inflammatory parameters in the smoker group. In our study we have not found that the magnitude of tobacco consumption has any influence on these inflammatory markers. Those studies have not analyzed either the relation between TNF- $\alpha$ levels in $\mathrm{EBC}$ and lung function parameters. One of the findings in our group of patients was a significant association between TNF- $\alpha$ levels in EBC and some pulmonary function tests, such as measuring the percentage of $\mathrm{FEV}_{1}$ and FVC.

Our group has also studied possible associations between age, gender or weight and TNF- $\alpha$ levels and our results are slightly different from those reported 
Table 2 Association between lung function parameters andTNF- $\alpha$ levels in serum and EBC

\begin{tabular}{|c|c|c|c|}
\hline & Number & Mean value & Significance \\
\hline \multicolumn{4}{|l|}{ TNF- $\alpha$ serum } \\
\hline Smokers & 8 & 5.50 & N.S. \\
\hline Nonsmokers & 9 & 5.52 & \\
\hline \multicolumn{4}{|l|}{ TNF- $\alpha$ EBC } \\
\hline Smokers & 8 & 4.46 & N.S. \\
\hline Nonsmokers & 9 & 4.34 & \\
\hline \multicolumn{4}{|l|}{ FVC ml } \\
\hline Smokers & 8 & 4232.86 & N.S. \\
\hline Nonsmokers & 9 & 4778.89 & \\
\hline \multicolumn{4}{|l|}{ FVC \% } \\
\hline Smokers & 8 & 99.77 & 0.079 \\
\hline Nonsmokers & 9 & 97.42 & \\
\hline \multicolumn{4}{|l|}{$\mathrm{FEV}_{1} \mathrm{ml}$} \\
\hline Smokers & 8 & 3424.29 & N.S. \\
\hline Nonsmokers & 9 & 4015.56 & \\
\hline \multicolumn{4}{|l|}{$\mathrm{FEV}_{1} \%$} \\
\hline Smokers & 8 & 104.60 & 0.058 \\
\hline Nonsmokers & 9 & 104.21 & \\
\hline \multicolumn{4}{|l|}{$\mathrm{FEV}_{1} / \mathrm{FVC}$} \\
\hline Smokers & 8 & 81.31 & N.S. \\
\hline Nonsmokers & 9 & $84.4 I$ & \\
\hline
\end{tabular}

Abbreviations: $\mathrm{EBC}$, exhaled breath condensate; $\mathrm{FEV}_{\text {, }}$, forced respiratory volume in one second; FVC, forced vital capacity;TNF- $\alpha$, tumor necrosis factor alpha.

in the literature. Himmerich et al showed in one report a significant influence of age on the serum TNF- $\alpha$ levels (increasing with age), but in our series we have not confirmed their findings. However, we must acknowledge that our control group is significantly younger than the study one and this can limit results interpretation. In the same report, Himmerich and colleagues also confirmed an association between weight and TNF- $\alpha$ levels that we have not been able to confirm, and a slight influence of gender on the serum TNF- $\alpha$ levels, similar to the one we have found in our patients. Nevertheless, these authors did not measure TNF- $\alpha$ levels in EBC.

We can conclude that EBC is a potential useful tool for the determination of inflammatory parameters in distal airways. TNF- $\alpha$ levels can be one of the important parameters we can use. However, further studies with larger number of patients are needed to confirm the results found in the present study.

\section{Disclosure}

The authors report no conflicts of interest in the present study.

\section{References}

1. Repine JE, Bast A, Lankhorst I. Oxidative stress in chronic obstructive pulmonary disease. Oxidative Stress Study Group. Am J Respir Crit Care Med. 1997;156:341-357.

2. Morrow JD, Frei B, Longmire AW, et al. Increase in circulating products of lipid peroxidation (F2-isoprostanes) in smokers. $N$ Engl $J$ Med. 1995;332:1198-1203.

3. Mutlu GM, Garey KW, Robbins RA, Danziger LH, Rubinstein I. Collection and analysis of exhaled breath condensate in humans. Am J Respir Crit Care Med. 2001;164:731-737.

4. Montuschi P, Barnes PJ. Analysis of exhaled breath condensate for monitoring airway inflammation. Trends Pharmacol Sci. 2002;23:232-237.

5. Scheideler L, Manke HG, Schwulera U, Inacker O, Hammerle H. Detection of nonvolatile macromolecules in breath: a possible diagnostic tool? Am Rev Respir Dis. 1993;148:778-784.

6. Manolis A. The diagnostic potential of breath analysis. Clin Chem. 1983;29:5-15.

7. Kharitonov SA, Barnes PJ. Exhaled markers of pulmonary disease. Am J Respir Crit Care Med. 2001;163:1693-1722.

8. Park WY, Goodman RB, Steinberg KP, et al. Cytokine balance in the lungs of patients with acute respiratory distress syndrome. Am J Respir Crit Care Med. 2001;164:1896-1903.

9. Sack U, Scheibe R, Wötzel M, et al. Multiplex analysis of cytokines in exhaled breath condensate. Cytometry A. 2006;69:169-172.

10. Yamamoto C, Yoneda T, Yoshikawa M, et al. Airway inflammation in COPD assessed by sputum levels of interleukin-8. Chest. 1997;112:505-510.

11. Di Stefano A, Capelli A, Lusuardi M, et al. Severity of airflow limitation is associated with severity of airway inflammation in smokers. $\mathrm{Am}$ J Respir Crit Care Med. 1998;158:1277-1285.

12. Takabatake N, Nakamura H, Abe S, et al. The relationship between chronic hypoxemia and activation of the tumor necrosis factor-alpha system in patients with chronic obstructive pulmonary disease. Am J Respir Crit Care Med. 2000;161:1179-1184.

13. Miller MR, Hankinson J, Brusasco V, et al. ATS/ERS Task Force. Standardisation of spirometry. Eur Respir J. 2005;26:319-338.

14. Garey KW, Neuhauser MM, Robbins RA, Danziger LH, Rubinstein I. Markers of inflammation in exhaled breath condensate of young healthy smokers. Chest. 2004;125:22-26.

15. Carpagnano GE, Kharitonov SA, Foschino-Barbaro MP, et al. Increased inflammatory markers in the exhaled breath condensate of cigarette smokers. Eur Respir J. 2003;21:589-593.

16. Horváth I, Hunt J, Barnes PJ, et al. Exhaled breath condensate: methodological recommendations and unresolved questions. Eur Respir J. 2005;26:523-548.

17. Kharitonov SA, Barnes PJ. Exhaled biomarkers. Chest. 2006;130:1541-1546.

18. Vernooy JH, Küçükaycan M, Jacobs J, et al. Local and systemic inflammation in patients with chronic obstructive pulmonary disease. Am J Respir Crit Care Med. 2002;186:1218-1224.

19. Ryder MI, Saghizadeh M, Ding Y, Nguyen N, Soskolne A. Effects of tobacco smoke on the secretion of interleukin-1 $\beta$, tumor necrosis factor- $\alpha$, and transforming growth factor- $\beta$ from peripheral blood mononuclear cells. Oral Microbiol Immunol. 2002;17:331-336.

20. Mian MF, Lauzon NM, Stämpfli MR, Mossman KL, Ashkar AA. Impairment of human NK cell cytotoxic activity and cytokine release by cigarette smoke. J Leukoc Biol. 2008;83:774-784.

21. Himmerich H, Fulda S, Linseisen J, et al. TNF-alpha, soluble TNF receptor and interleukin-6 plasma levels in the general population. Eur Cytokine Netw. 2006;17:196-201. 